\title{
Editorials
}

\section{Skill-mix change and the general practice workforce challenge}

Faced with an ageing population living with increasingly complex health needs and a shortage of GPs and nursing staff, primary care is experiencing unprecedented pressure. Workforce transformation based around new models of care and 'skill-mix' change in the form of 5000 new "nonmedical roles' to operate alongside GPs is an aspirational solution, ${ }^{1}$ though generating the right balance of GPs/non-GPs is not without controversy. ${ }^{2}$ Although practice nurses have been working in extended roles in general practice for a long time ${ }^{3}$ there are other 'new' roles emerging. These encompass both the integration into primary care teams of new types of professional (for example, physician associates), and existing professional roles operating in new ways (for example, paramedics), typically with the expressed aim of releasing the capacity of GPs. ${ }^{4}$ Thus, skill-mix change may be perceived as a straightforward and common-sense response, 'substituting' hard-to-recruit GPs with other, non-medical, health professionals. Recently, a House of Lords Select Committee on the sustainability of the NHS has added its weight to other reports 4,5 calling for the greater inclusion of non-medical workforce working under new models of care. ${ }^{6}$ Re-designing the workforce through skill-mix change is a considerable challenge for organisations, which may indeed bring benefits. ${ }^{5}$ However, the literature indicates the necessity to understand the implications of changing skill-mix if it is to deliver on its promises.

\section{'SKILL-MIX' DEFINED AND CHANGE CLASSIFIED}

Skill-mix has been conceptualised in three ways to mean: (1) the range of competencies possessed by an individual healthcare worker; (2) the ratio of senior to junior staff within a particular discipline; and (3) the mix of different types of staff in a team/ healthcare setting. ${ }^{7}$ Skill-mix changes have been classified into four broad role modifications: ' enhancement (for example, extension of a primary care practice nurse's role without need for supervision); substitution Ifor example, a less expensive prescribing pharmacist expanding their role into the medical domain to substitute partially for a GP); delegation (for example, a GP transferring tasks to a physician associate under supervision); and finally innovation (for example, a physiotherapist leading musculoskeletal clinics that provide a new/enhanced service in primary care).

This classification not only helps distinguish the different aspects of change that may be leading to better-quality care, integration, work displacement, or cost-saving but it also enables the identification of cost implications that are often underestimated.? For example, time/ cost-savings from substitution are possible only if the more expensive worker gives up tasks delegated to the less expensive worker or does not incur extra work through supervision efforts. Otherwise, such changes lead to duplication of tasks with consequences for cost-savings. New roles may also extend the scope of general practice, generating additional work that may or may not be fully compensated. In addition there may be wider challenges in making skill-mix changes in terms of inter-professional relations, professional identities, complexity/extent of workload, supervision, and pressure on wages.

\section{THE PRIMARY CARE EVIDENCE BASE FOR SKILL-MIX CHANGE}

To synthesise the evidence, a rapid scoping review of the international literature on skill-mix change in primary care was conducted, focusing specifically on a range of new non-medical roles currently being planned or implemented in UK general practice. The review was informed by the above classification ${ }^{7}$ and highlighted key insights into the impact and implementation of such roles. ${ }^{8}$ Medical and social science databases (MEDLINE/PubMed; PsycINFO; PROSPERO; ASSIA; CINAHL; Cochrane Library; Scopus; HMIC; AMED; Web of Science; Embasel and the grey literature Igovernmental, policy, and health-related charity sources) were searched from 2004 (when a comprehensive review of reviews ${ }^{7}$ was publishedl to the present. A combination of general search terms (for example, skill-mix; new roles; workforce change; primary care; general practice), specific terms related to the particular new roles of interest (for example, advanced practitioner/advanced nurse practitioner; physician associate; clinical pharmacist; paramedic; physiotherapist; medical assistant; mental health assistant; care navigator), and screening for relevance enabled the retrieval of approximately 70 methodologically diverse papers focusing on either the impact or process of introducing new non-medical roles in this setting. Qualitative and quantitative research was included. Review papers were mainly international, whereas the majority of single studies were UK based with several from the US, Canada, and the Netherlands, a smaller number from Sweden, Germany, Australia, New Zealand, and Spain, and one inter-centre European study. ${ }^{8}$

Evidence for skill-mix change in general practice from the review is patchy ${ }^{8}$ but suggests broadly that it can support care that is appropriate, safe, and satisfactory for patients. Importantly, however, such changes do not necessarily reduce GP workload or costs, at least in the short term, and may potentially increase both. Costeffectiveness is poorly evaluated in such studies. Instead, studies largely address the implementation of single roles in isolation from organisational arrangements and assume that shifts will offer better value for money through targeting resources more effectively, improving access to services, and raising the quality of care. Nonetheless, some of this research usefully highlights the challenges and wider consequences (including unintended consequences) of implementing skill-mix change.

\section{CONSIDERATIONS FOR THE IMPLEMENTATION OF SKILL-MIX CHANGE IN GENERAL PRACTICE}

Perhaps unsurprisingly, challenges for general practice teams resonate with questions raised of earlier skill-mix changes. ${ }^{7.9}$ Specifics identified in the scoping review can thus be grounded in the broader 'organisational' issues referenced above.

\section{Are the function and scope of any 'new' roles clearly articulated?}

Studies indicate that clarification of the function of skill-mix changes (for example, substitution, enhancement, delegation, innovation, or a mixturel remains a key challenge. ${ }^{7-9}$ Where this is blurred, integration into general practice might be hindered, such as when a physician associate cannot meet GPs' expectations that they will only act as substitutes.

Defining the scope of newly introduced roles is also important - particularly if costs are to be contained. Practice staff may not fully understand the remit of new roles, which, in turn, can contribute to inappropriate use of the worker, increased 
workload, higher costs, lower staff morale/ productivity, reduced continuity of care for patients, and inter-professional tensions. ${ }^{8,10}$

\section{Is there a plan for actively managing skill-mix change?}

In primary care, there is a need for active management to ensure that duplication of work is avoided and that inefficiencies do not arise from 'transaction costs' associated with work in a larger team of individuals., ${ }^{8} 10$ Coordination may also be needed to maintain continuity and avoid any potential fragmentation of care due to the involvement of multiple professionals.

\section{Is the status of any new roles clear?}

Earlier work indicated how regulatory provisions can affect the feasibility of skill-mix change. 7,10 The continued need for supporting regulation can be seen in the lack of prescribing ability in physician associate/paramedic roles, which may limit integration in general practice. Notwithstanding, removing regulatory restrictions is challenging and costly. ${ }^{10}$

\section{Have wider system effects been considered?}

Workforce re-design crosses traditional primary care boundaries and needs to be considered in wider system design and governance arrangements. This has particular resonance in light of the shift to primary care at scale and neighbourhood working under new models of care. ${ }^{8}$ Unfortunately, research on the importance of organisational context/arrangements and the interdependent wider system effects of skill-mix change is largely absent from this body of work and represents an important gap in knowledge. Identifying the healthcare needs of a particular population and matching the organisation's workforce skill-set appropriately is also important. ${ }^{11}$

\section{CONCLUSION}

Although skill-mix change is recommended as a solution to workforce challenges in general practice, it may not always achieve the intended aims. The specifics of how nonmedical professionals and GPs will work together need to be clarified and mutually agreed. ${ }^{12}$ The replacement of GPs with less expensive non-medical professionals may result in supplementation rather than substitution, leading to a range of unintended consequences. These include reduced productivity/continuity of care and increased demand/costs. For substitution to be successful in general practice, GPs need to stop doing the work they hand over to non-medical personnel to avoid duplication and recognise that substitution will always be partial because non-medical staff cannot provide the full range of GP care.

Organisational/operational issues that are important in skill-mix change in general practice include the need to match planned skill-mix changes with population needs as part of appropriate workforce planning and deployment, and attention to role expectations, professional boundaries, legal issues, and active management of change. Evidence about the wider system effects involved in workforce re-design is currently lacking but crucially important in light of the aspiration to new models of care. Given these challenges, Buchan and colleagues' question 'If changing skillmix is the answer, what is the question?"1 remains a pertinent one to ponder in primary care today.

\section{Pauline Nelson,}

Research Fellow, Alliance Manchester Business School, University of Manchester, and National Institute for Health Research (NIHR) Collaboration for Leadership in Applied Health Research and Care (CLAHRC) Greater Manchester, Manchester.

\section{Anne-Marie Martindale,}

Research Associate, Centre for Primary Care, University of Manchester, and NIHR CLAHRC Greater Manchester, Manchester.

\section{Anne McBride,}

Senior Lecturer in Employment Studies, Alliance Manchester Business School, University of Manchester, and NIHR CLAHRC Greater Manchester, Manchester.

\section{Kath Checkland}

Professor of Health Policy and Primary Care, Centre for Primary Care, University of Manchester, Manchester.

\section{Damian Hodgson,}

Professor of Organisational Analysis, Alliance Manchester Business School, University of Manchester; Lead, Organising Healthcare Programme, NIHR CLAHRC Greater Manchester; and Deputy Director, Health Services Research Centre, Alliance Manchester Business School, University of Manchester, Manchester.

\section{Funding}

This project was funded by the NIHR CLAHRC Greater Manchester. The NIHR CLAHRC Greater Manchester is a partnership between providers and commissioners from the NHS, industry, and the third sector, as well as clinical and research staff from the University of Manchester. The views expressed in this article are those of the authors and not necessarily those of the NHS, NIHR, or the Department of Health.

\section{Provenance}

Freely submitted; externally peer reviewed.

\section{Open access}

This article is Open Access: CC BY-NC 4.0 licence (http://creativecommons.org/licences/by-nc/4.0/).

\section{ADDRESS FOR CORRESPONDENCE}

\section{Pauline Nelson}

NIHR Collaboration for Leadership in Applied Health Research and Care Greater Manchester, Room C9, Alliance Manchester Business School (East), University of Manchester, Booth St East, Manchester M13 9SS, UK.

E-mail: pauline.nelsonamanchester.ac.uk

DOI: https://doi.org/10.3399/bjgp18X694469

\section{REFERENCES}

1. NHS England. General practice forward view. 2016. https://www.england.nhs.uk/wp-content/ uploads/2016/04/gpfv.pdf laccessed 11 Dec 2017).

2. Matthews-King A. GP training cuts necessary to allow HEE to 'develop physician associates' Pulse 2017: http://mww.pulsetoday.co.uk/ your-practice/practice-topics/education/ gp-training-cuts-necessary-to-allow-hee-todevelop-physician-associates/20034643.article laccessed 11 Dec 2017).

3. Laurant M, Harmsen M, Wollersheim H, et al The impact of nonphysician clinicians: do they improve the quality and cost-effectiveness of health care services? Med Care Res Rev 2009; 66(6 Suppl): 36S-89S.

4. Primary Care Workforce Commission. The future of general practice: creating teams for tomorrow. 2015. https://www.hee.nhs.uk/sites/ default/files/documents/WES_The-future-ofprimary-care.pdf laccessed 11 Dec 2017).

5. Imison C, Castle-Clarke S, Watson R. Reshaping the workforce to deliver the care patients need. London: Nuffield Trust, 2016. https://www.nuffieldtrust.org.uk/files/201701/reshaping-the-workforce-web-final.pdf laccessed 11 Dec 2017).

6. House of Lords Select Committee on the Long-Term Sustainability of the NHS. Report of session 2016-17. 2017. https://publications. parliament.uk/pa/ld201617/ldselect/ ldnhssus/151/151.pdf laccessed 11 Dec 2017)

7. Sibbald B, Shen J, McBride A. Changing the skill-mix of the healthcare workforce. $J$ Health Serv Res Policy 2004; 9(Suppl 1): 28-38.

8. Nelson PA, Martindale A-M, McBride A, Hodgson D. Greater Manchester primary care workforce strategy: rapid literature review. CLAHRC GM, 2017. http://clahrc-gm.nihr.ac.uk/ wp-content/uploads/Salford_GMWF_Lit-review. pdf laccessed 11 Dec 2017).

9. Richardson G, Maynard A, Cullum N, Kindig D. Skill mix changes: substitution or service development? Health Policy 1998; 45(2): 119-132

10. Sibbald B, McBride A, Birch B. Labour substitution and efficiency in healthcare delivery: general principles and key messages. London: Centre for Workforce Intelligence, 2011.

11. Buchan J, Ball J, O'May F. If changing skill mix is the answer, what is the question? J Health Serv Res Policy 2001; 6(4): 233-238.

12. Jones R. Deconstructing the doctor. $\mathrm{Br} J$ Gen Pract 2017; DOI: https://doi.org/10.3399/ bjgp17X692177. 